\title{
Trauma severity and mandibular fracture patterns in a regional trauma center
}

Hyeok Lee,

Kwang Seog Kim,

Jun Ho Choi, Jae Ha Hwang, Sam Yong Lee

Department of Plastic and

Reconstructive Surgery, Chonnam

National University Medical School,

Gwangju, Korea
Background: Mandibular fractures are one of the most common types of facial fractures, the treatment of which can be delayed due to the severity of the trauma resulting in an increase of complications; thus, early evaluation of trauma severity at the time of visit is important. In South Korea, trauma patients are triaged and intensively treated in designated regional trauma centers. This study aimed to analyze the relationship between trauma severity and mandibular fracture patterns.

Methods: A medical records review was performed on patients who visited the regional trauma center at our hospital for mandibular fracture between 2009 and 2018. Epidemiologic data and mandibular fracture patterns were analyzed and compared with the conventional facial injury severity scale (FISS).

Results: Among 73 patients, 51 were classified as non-severe trauma patients and 22 as severe trauma patients. A higher trauma severity was associated with older age (odds ratio [OR], 1.164; 95\% confidence interval [CI], 1.057-1.404) and lower risk was associated with fractures located in the angle $(0 \mathrm{R}, 0.001 ; 95 \% \mathrm{Cl}, 0-0.022)$, condylar process $(\mathrm{OR}, 0.001 ; 95 \% \mathrm{Cl}, 0-0.28)$, and coronoid process (OR, 0.004; 95\% $\mathrm{Cl}, 0-0.985)$. The risk was lower when the injury mechanism was a pedestrian traffic accident (OR, 0.004; $95 \% \mathrm{Cl}, 0-0.417$ ) or fall (OR, $0.004 ; 95 \% \mathrm{Cl}, 0-0.663$ ) compared with an in-car traffic accident. Higher FISS (OR, 1.503; 95\% Cl, 1.155-2.049) was associated with a higher trauma severity. The proposed model was found to predict the trauma severity better than the model using FISS $(p<0.001)$.

Conclusion: Age, location of mandibular fractures, and injury mechanism showed significant relationships with the trauma severity. Epidemiologic data and patterns of mandibular fractures could predict the trauma severity better than FISS.

Keywords: Facial injuries / Mandibular fracture / Trauma center

\section{INTRODUCTION}

The incidence and etiology of facial fractures manifest differently depending on various factors, including environmental, cultural, and socio-economic factors. Among the facial frac-

\section{Correspondence: Kwang Seog Kim}

Department of Plastic and Reconstructive Surgery, Chonnam National University

Medical School, 42 Jebong-ro, Dong-gu, Gwangju 61469, Korea

E-mail: pskim@chonnam.ac.kr

This article is a master's thesis of Hyeok Lee submitted in 2020.

Received September 29, 2020 / Revised October 15, 2020 / Accepted October 20, 2020 tures, mandible fractures are common, along with fractures of the nasal bone, the orbital wall, and the zygomaticomaxillary complex (ZMC). The mandible is essential for speaking, biting, and chewing [1]. Like other fractures, mandibular fractures lead to a decrease of the quality of life and cause severe functional disability and social costs. Thus, mandibular fractures must be treated to recover the pretrauma condition [2]. If the displacement is not severe, conservative treatment, including a closed reduction with an intermaxillary fixation, can be performed. However, in case of severe displacement and dysfunc- 
tion, appropriate reduction and rigid fixation may be necessary [3]. However, if the patient's general condition is poor, the treatment may be delayed, and the risk of postoperative complications is high. Therefore, assessment of the severity of patient's condition at the time of the visit is necessary.

Regional trauma centers have been established to provide intensive treatment to severe trauma patients. A regional trauma center refers to a treatment center specialized in treating severe trauma patients with multiple fractures or bleeding due to traffic accidents (TA) or falls, it can provide immediate patient resuscitation, emergency surgery, and procedures, and it is equipped with relevant medical tools and human resources to provide an optimal treatment, such as critical care. In Korea, five institutions were designated as regional trauma center and were supported by the government since 2012. They opened for the first time in 2014, and 15 centers are currently in operation in hospitals nationwide. When a trauma patient visits the emergency room, regional trauma centers assign the injury severity score by considering the affected body region and the severity of each injury. Usually, severe trauma patients are those with a score of at least 15 points [4]. Another method to assess the severity of facial trauma is facial injury severity scale (FISS) (Table 1). FISS is a clinically useful index because it can predict the severity of facial injuries and is an indicator of the hospital length of stay [5].

Table 1. Facial injury severity score

\begin{tabular}{llc}
\hline Anatomic region & \multicolumn{1}{c}{ Fracture type } & Points \\
\hline Mandible & Dentoalveolar & 1 \\
& Each fracture of body/ramus/symphysis & 2 \\
& Each fracture: condyle/coronoid & 1 \\
Mid-face & Each midfacial fracture is assigned one point, unless & \\
& part of a complex & 1 \\
& Dento Alveolar & 2 \\
& Le Fort I & 4 \\
& Le Fort II & 6 \\
& Le Fort III & (Unilateral Le Fort fractures are assigned half the \\
& numeric value) & \\
& NOE & 3 \\
& ZMC & 1 \\
& Nasal & 1 \\
& Orbital roof/rim & 1 \\
& Displaced frontal sinus/bone fractures & 5 \\
Upper face & Non-displaced fractures & 1 \\
\hline Facial laceration & Over 10 cm long & 1 \\
\hline
\end{tabular}

The facial injury severity score (FISS) is the summation of the above points in an individual patient.

NOE, naso-orbital ethmoid; ZMC, zygomaticomaxillary complex.
The purpose of this study was to classify the patients who visited a single regional trauma center for mandibular fracture into severe trauma patients and non-severe trauma patients and to collect data, such as epidemiologic data, mandibular fracture patterns, and accompanying injuries, in order to find its relationship with severe trauma patients. By identifying the trauma that leads to mandibular fractures, predicting trauma severity using significant predictors, and further enabling more efficient allocation of the limited trauma-related resources, this study is expected to help quickly classify and treat patients with high trauma severity.

\section{METHODS}

\section{Subjects}

Seventy-three patients who received treatment for mandibular fractures at a regional trauma center in our hospital from January 2009 to December 2018 were assigned to group A (non-severe trauma patients) or group B (severe trauma patients). To assess trauma severity, the injury severity score of patients who visited the hospital before being designated to the regional trauma center was calculated by reviewing the medical records.

\section{Data collection}

The medical records and computed tomography images of the patients were reviewed. Age, sex, injured season, laterality, location of fractures, other concomitant facial fractures, injury mechanism, soft tissue injury were recorded and FISS was calculated. The season was classified as spring for March through May, summer for June through August, autumn for September to November, and winter for December to February. The concomitant facial bone fracture was classified as a ZMC, orbital wall, nasal bone, or frontal sinus/skull, depending on the location. Injury mechanism was classified as in-car TA, pedestrian TA, motorbike/bicycle, falls, assault, or work accident.

\section{Statistical analysis}

After data collection, statistical analyses were performed using SPSS version 25.0 (IBM Corp., Armonk, NY, USA). To compare the differences between the groups for each variable, $t$-tests were performed on continuous variables and chi-square tests on categorical variables. Furthermore, to assess the trauma severity using predictive variables, multivariate logistic regression analysis was performed, and the $95 \%$ confidence interval (CI) and $p$ value of each odds ratio were obtained using the likelihood ratio test. As FISS includes mandibular fracture, concomitant facial fractures, and soft tissue injury in its scoring system, the statistics can be skewed because of multicollinearity. Thus, univariate 
logistic regression analysis was performed using only FISS. The author compared the predictive power of the predictive model using the existing FISS and the predictive model with several predictive variables added to the FISS. Furthermore, the statistical significance level of $p$-value $<0.05$ was used.

\section{RESULTS}

\section{Descriptive statistics}

From January 2009 to December 2018, of 73 patients, 51 were assigned to group A and 22 to group B. The average age of patients in group A was $39.3 \pm 21.4$ years, and the sex ratio was approximately 3.25:1 (39 males and 12 females). The average age of patients in group B was 52.0 \pm 17.0 years, and the sex ratio was approximately 4.5:1 (18 males and four females) (Table 2). The most common season that injury occurred was summer for groups A and B (Fig. 1). Group B had a significantly older than group $\mathrm{A}$.

No significant differences were found in the laterality of the mandibular fractures between the two groups. For location, symphysis comprised the highest proportion for both groups, and there were significantly more body fractures in group $B$

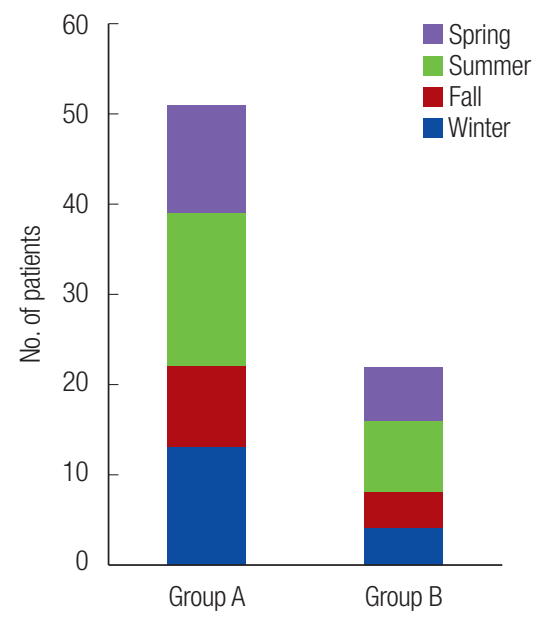

Fig. 1. Facial fractures by season. Fractures occurred most commonly in the summer for both groups. Group A, non-severe trauma patients; Group B, severe trauma patients.

Table 2. Epidemiologic data of patients

\begin{tabular}{lccc}
\hline Variable & $\begin{array}{c}\text { Non-severe trauma patients } \\
(\mathrm{n}=51)\end{array}$ & $\begin{array}{c}\text { Severe trauma patients } \\
(\mathrm{n}=22)\end{array}$ & $p$-value \\
\hline Age $(\mathrm{yr})$ & $39.3 \pm 21.4$ & $52.0 \pm 17.0$ & $0.016^{\mathrm{a}}$ \\
Sex & & & 0.762 \\
$\quad$ Male & $39(76.5)$ & $18(81.8)$ & \\
Female & $12(23.5)$ & $4(18.2)$ & \\
\hline
\end{tabular}

Values are presented as mean $\pm \mathrm{SD}$ or number (\%).

a) Statistically significant, $p<0.05$.
(Pearson's chi-square test, $p=0.002$ ) (Table 3). In total, 107 mandibular fractures were recorded in both groups. The average number of mandibular fractures in group A was $1.45 \pm 0.58$ (total of 74) and that in group B was $1.50 \pm 0.67$ (total of 33), but no significant difference was found. Furthermore, there were 50 concomitant facial fractures in 30 patients in group A and 27 concomitant facial fractures in 12 patients in group B. However, no significant differences were observed in whether there were concomitant facial fractures between the two groups. ZMC fracture comprised the highest proportion in both groups, but there was still no significant difference (Table 4). Soft tissue injury occurred in 24 patients in group A (47.1\%) and 18 patients in group B (81.8\%). Group B had a statistically significant relationship with a soft tissue injury, and the FISS of group B was higher (Table 5). No significant differences were noted in the injury mechanism between the two groups (Table 6).

Table 3. Patterns of mandibular fractures

\begin{tabular}{lccc}
\hline Variable & $\begin{array}{c}\text { Non-severe trauma } \\
\text { patients }(n=51)\end{array}$ & $\begin{array}{c}\text { Severe trauma } \\
\text { patients }(n=22)\end{array}$ & $p$-value \\
\hline Laterality & $16(31.4)$ & $6(27.2)$ & 0.808 \\
Left & $21(41.2)$ & $8(36.4)$ & \\
Right & $14(27.4)$ & $8(36.4)$ & \\
Both & & & \\
Location & 21 & 12 & 0.317 \\
Symphysis, parasymphysis & 1 & 6 & $0.002^{\text {a) }}$ \\
Body & 11 & 2 & 0.32 \\
Angle & 13 & 5 & 1 \\
Ramus & 13 & 3 & 0.361 \\
Condylar process & 10 & 2 & 0.326 \\
Coronoid process & $1.45 \pm 0.58$ & $1.50 \pm 0.67$ & 0.752 \\
\hline No. of mandibular fractures & & & \\
\hline Values are presented as number (\%) or mean \pm SD. & & \\
a)Statistically significant, $p<0.05$. & &
\end{tabular}

Table 4. Concomitant facial fractures

\begin{tabular}{lccl}
\hline Variable & $\begin{array}{c}\text { Non-severe trauma } \\
\text { patients }(n=51)\end{array}$ & $\begin{array}{c}\text { Severe trauma } \\
\text { patients }(n=22)\end{array}$ & $p$-value \\
\hline Concomitant facial fractures & & & \\
$\quad$ Presence & 30 & 12 & 0.799 \\
ZMC & 25 & 11 & 1 \\
Orbital wall & 14 & 9 & 0.282 \\
Nasal bone & 8 & 3 & 1 \\
Frontal sinus, skull & 3 & 4 & 0.188 \\
Soft tissue injury & $24(47.1)$ & $18(81.8)$ & $0.009^{\text {a) }}$ \\
FISS & $3.4 \pm 1.6$ & $5.0 \pm 2.6$ & $0.01^{\text {a) }}$ \\
\hline
\end{tabular}

Values are presented as number (\%) or mean \pm SD.

ZMC, zygomaticomaxillary complex; FISS, facial injury severity scale.

a) Statistically significant, $p<0.05$. 


\section{Logistic regression analysis}

The results of the multivariate logistic regression analysis using the predictive variables except FISS are summarized in Fig. 2. Sex, season that injury occurred, laterality, concomitant facial fractures, and soft tissue injury had no relationship with the risk of having a severe trauma classification, but it was significantly higher with increasing age (odds ratio [OR], 1.164; 95\% CI, 1.057-1.404). Furthermore, the risk was lower when the fracture was located in the angle (OR, 0.001; 95\% CI, 0-0.022), condylar process (OR, $0.001 ; 95 \% \mathrm{CI}, 0-0.28$ ), or coronoid process (OR, 0.004; 95\% CI, 0-0.985). Moreover, when "in-car TA" was used as a reference, injury mechanism was significantly lower

Table 5. Soft tissue injury and FISS

\begin{tabular}{lccc}
\hline Variable & $\begin{array}{c}\text { Non-severe trauma } \\
\text { patients }(n=51)\end{array}$ & $\begin{array}{c}\text { Severe trauma } \\
\text { patients }(n=22)\end{array}$ & $p$-value \\
\hline Soft tissue injury & $24(47.1)$ & $18(81.8)$ & $0.009^{\text {a) }}$ \\
FISS & $3.4 \pm 1.6$ & $5.0 \pm 2.6$ & $0.01^{\text {a) }}$ \\
\hline
\end{tabular}

Values are presented as number (\%) or mean \pm SD.

FISS, facial injury severity scale.

a)Statistically significant, $p<0.05$. for pedestrian TA (OR, 0.004; 95\% CI, 0-0.417) and falls (OR, 0.004; 95\% CI, 0-0.663). In the univariate logistic regression analysis using FISS, higher FISS (OR, 1.503; 95\% CI, 1.1552.049) was associated with a high trauma severity (Fig. 3).

\section{ROC curves and AUC}

Each receiver operating characteristic (ROC) curve was generated when the predictive variables, except FISS, were used and

Table 6. Mechanism of injury

\begin{tabular}{lccc}
\hline Variable & $\begin{array}{c}\text { Non-severe trauma } \\
\text { patients }(n=51)\end{array}$ & $\begin{array}{c}\text { Severe trauma } \\
\text { patients }(n=22)\end{array}$ & $p$-value \\
\hline Mechanism of injury & & & 0.296 \\
In-car TA & $8(15.7)$ & $7(31.8)$ & \\
Pedestrian TA & $3(5.9)$ & $3(13.7)$ & \\
Motorbike/bicycle & $7(13.7)$ & $2(9.1)$ & \\
Falls & $20(39.2)$ & $5(22.7)$ & \\
Assault & $7(13.7)$ & $1(4.5)$ & \\
Work accident & $6(11.8)$ & $4(18.2)$ & \\
\hline
\end{tabular}

Values are presented as number (\%).

$T$ A, traffic accident.

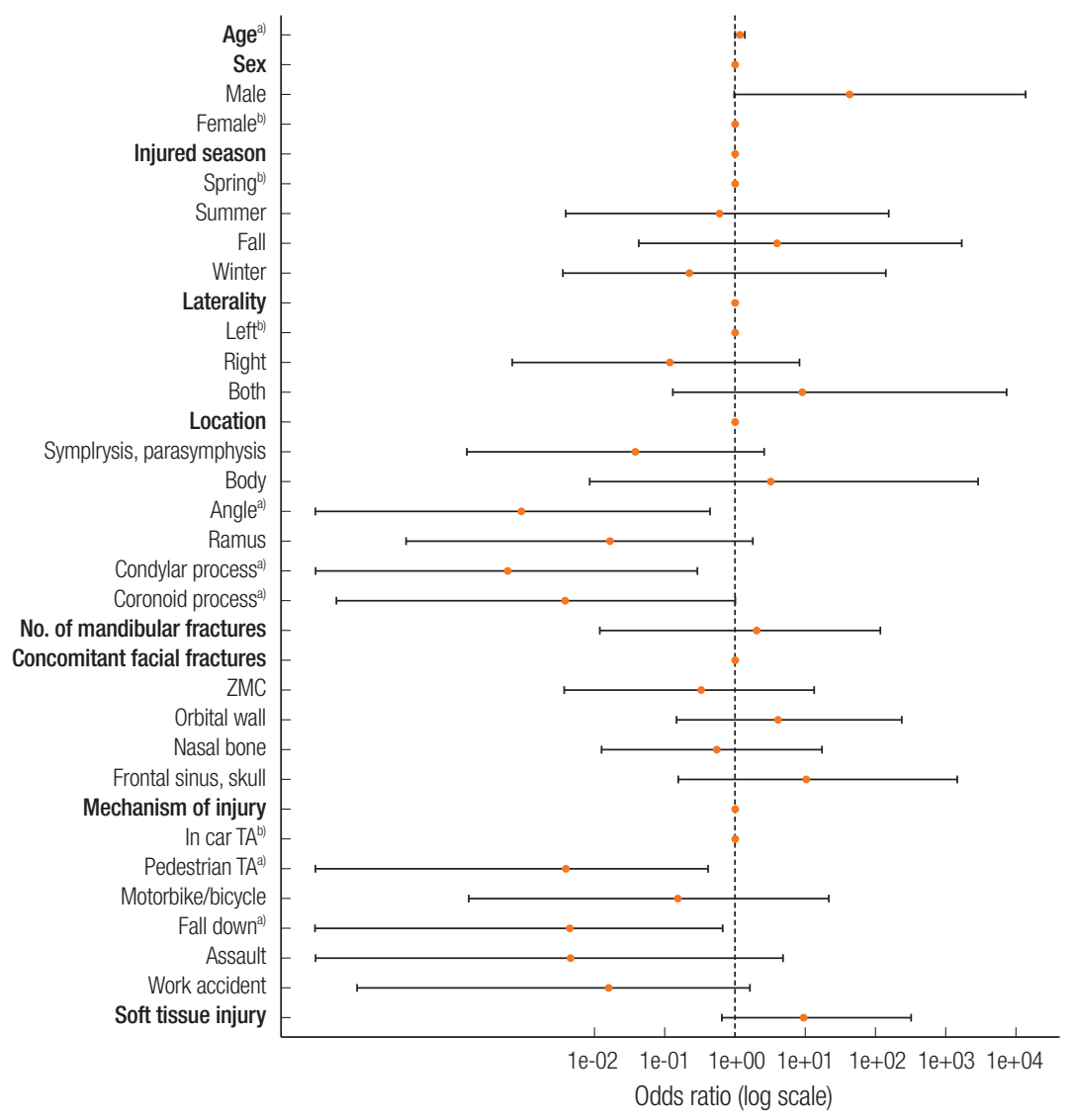

Fig. 2. Multivariate logistic regression analysis for the predictors of severe trauma patients (except FISS). Severe trauma patients were significantly associated with older age and fewer fractures in the angle, condylar process, and coronoid process. Moreover, when "in-car TA" was used as a reference, the injury mechanism was significantly lower for pedestrian TA and falls. FISS, facial injury severity scale; TA, traffic accident; ZMC, zygomaticomaxillary complex. ${ }^{\text {a) }}$ Statistically significant, $p<0.05 ;{ }^{\text {b) }}$ Reference. 


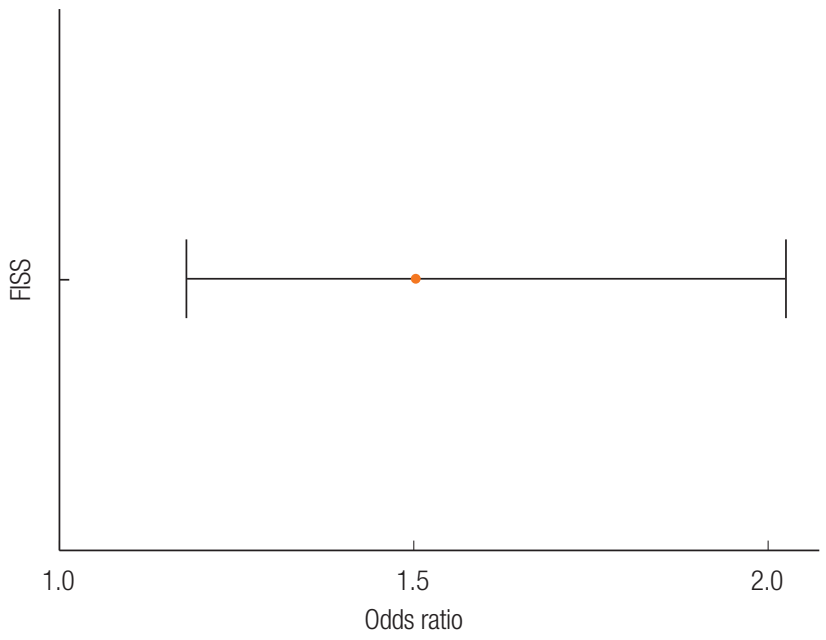

Fig. 3. Univariate logistic regression analysis for facial injury severity scale (FISS) of severe trauma patients. FISS values were significantly higher in severe trauma patients.

when only FISS was used (Fig. 4). The area under the curve (AUC) obtained using the predictive variables except FISS was 0.943 , and its cutoff value was 0.497 , while the AUC obtained using FISS was 0.690 , and its cutoff value was 4 . The results of comparing the AUCs from the two models using Delong's test for two correlated ROC curves showed that the model using the predictive variables except FISS was significantly better than using FISS at predicting severe trauma patients $(p<0.001)$.

\section{DISCUSSION}

The mandible is an important facial bone structure that perform many functions, and its fracture can cause severe functional disability and social costs. According to recent research, facial fractures most commonly occur in the third decade of life [6]. In the present study, patients with mandibular fractures were older than in the previous reports, and age was statistically significantly higher among severe trauma patients. This is thought to occur because older people have a higher risk of severe trauma exposure than younger people. Even though men were found to have a higher trauma severity in our data, the difference was not statistically significant. Many recent studies reported that facial fractures most commonly occur in the summer and rarely in the winter [1,7]. This was also thought to be related to the higher outdoor activities during summer, resulting in more frequent trauma. Although a similar trend was seen in this study, season did not have a strong impact on the severity of injury.

It can be expected that the probability of bilateral occurrence of mandibular fractures and the occurrence of multiple fractures would be higher in severe trauma patients. Such a rela-
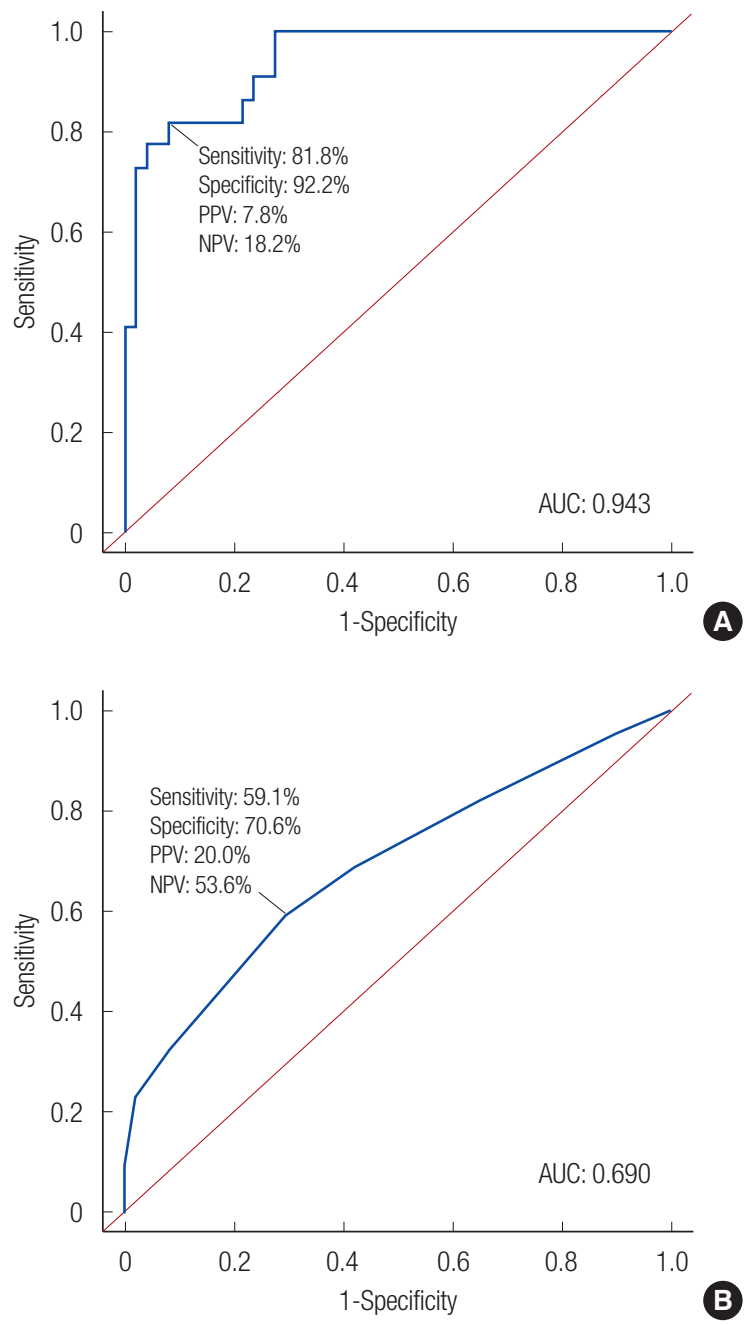

Fig. 4. (A) ROC curve using the predictive variables other than FISS. AUC: 0.943 (95\% CI, 0.893-0.993), cutoff value: 0.497. (B) ROC curve using FISS. AUC: 0.690 (95\% CI, 0.551-0.829), cutoff value: 4 . Delong's test for two correlated ROC curves $(p<0.001)$. ROC; receiver operating characteristic; FISS, facial injury severity scale; AUC, areas under curve; CI, confidence interval; NPV, negative predictive value; PPV; positive predictive value.

tionship was not found to be significant. Therefore, the severity of patient's condition and the severity of mandibular fractures are interpreted to be unrelated and independent. Morrow et al. [6] reported that condylar fractures accounts for the highest proportion of mandibular fractures, followed by body fractures, angle fractures, fractures of the symphyseal region, dentoalveolar fractures, ramus fractures, and coronoid fractures. In our study, a proportion of the affected area was different from this trend. The trauma severity was statistically significantly lower if the fracture was located in the angle, the condylar process, or the coronoid process. Descriptive statistics also showed that severe trauma patients had a high proportion of body fractures among the mandibular fractures. Thus, it can be assumed that the trauma severity is higher when the fracture is in the center 
rather than in the sides of the mandible. Even though concurrence of other facial bone fractures could be expected for severe trauma patients, no statistical differences were found. According to this finding we conclude that concomitant facial fractures do not always correlate with the severity of patient's condition.

Recently, there is a decreasing trend in facial trauma related to TA in many developed countries because of the strengthening of traffic safety regulations. For this reason, interpersonal violence has shown to relatively increase as an important cause [810]. In recent studies, the most frequent cause of injury was assault, followed by falls, sport accidents, TA, work accidents, and other causes [11]. In this study, the most common injury mechanism was in the order of TA, falls, work accidents, and assault. The most common types of TA were in the order of in-car TA, motorbike/bicycle, and pedestrian TA. This is thought to occur because there are more TA and work accidents than in urban regions, given that our hospital is a regional trauma center that also receives patients from the surrounding rural regions. According to the results of the analysis with "in-car TA" as the reference, patients with pedestrian TA and falls would have a significantly low trauma severity. This implies that the severity of mandibular fractures caused by "in-car TA" is relatively high. This hypothesis was generated because the mandible is struck by the steering wheel during "in-car TA," but in "pedestrian TA," the trunk and extremity are involved.

Furthermore, because significant soft tissue injury is more common in severe trauma, this study did show that the trauma severity was higher with soft tissue injury, but without statistical significance. It is possible that information about concomitant soft tissue injury was not accurate in the medical record or that the severity could be high even if there was no soft tissue injury due to blunt trauma.

FISS, which is an index that assesses the severity of craniofacial trauma, is a clinically simple but useful indicator that can predict the patients' severity of the injury, economic burden, and hospital length of stay [5]. In line with recent studies, this study found that higher FISS was associated with higher trauma severity and that the predictions could be made with the most optimal sensitivity and specificity when the cutoff is 4 points. Although the proposed model is quite complex because it includes more predictive variables than the model using FISS, the finding that its performance was significantly better is important.

After the establishment of the regional trauma center, we have classified and treated trauma patients more intensively and faster than before. Our regional trauma center opened on September 22, 2015. Among 48 patients who received mandibular fracture treatment before opening, eight (16.7\%) were classified as severe trauma patients; however, after opening, 14 out of 25 patients (56\%) were classified as severe trauma patients. Before the opening of the regional trauma center, data were inadequate, and the classification system for severe trauma patients through the injury severity scale was incomplete. It is presumed that with the implementation of a systematic classification system, the data quality will become higher soon. With the expansion of regional trauma centers, the preventable trauma death rate is decreasing. This is the first study that analyzed facial fractures of severe trauma patients at a regional trauma center in South Korea. The role of plastic surgeons for posttraumatic reconstruction and restoration of function is becoming increasingly important. Therefore, plastic surgeons should also have an interest in treating severe trauma patients; thus, this study can be the beginning of the efforts to accomplish that goal. However, the results of this study are limited; there is a possibility of statistical error due to the small sample size, it included only mandibular fractures among facial fractures, and it was conducted in a single center. Therefore, based on this study, it is necessary to analyze regional characteristics carefully through multicenter studies of patients with facial fractures admitted in regional trauma centers across the country.

\section{NOTES}

\section{Conflict of interest}

KSK, the editor-in-chief of the Archives of Craniofacial Surgery, is the corresponding author of this article. However, he played no role whatsoever in the editorial evaluation of this article or the decision to publish it. Except for that, no potential conflict of interest relevant to this article was reported.

\section{Ethical approval}

The study was approved by the Institutional Review Board of Chonnam National University Hospital (IRB No. CNUH-2020075) and performed in accordance with the principles of the Declaration of Helsinki.

\section{ORCID}

Hyeok Lee

Kwang Seog Kim

Jun Ho Choi

Jae Ha Hwang

Sam Yong Lee

https://orcid.org/0000-0003-4865-9595 https://orcid.org/0000-0002-6766-4640 https://orcid.org/0000-0002-4848-517X https://orcid.org/0000-0001-6992-8067 https://orcid.org/0000-0002-3185-2519

\section{REFERENCES}

1. Kwon HJ, Han J, Kim JH, Jung HY, Kim JY, Yoon SH, et al. Clinical epidemiologic study of facial bone fractures in Daegu. 
J Korean Soc Plast Reconstr Surg 2007;34:365-70.

2. Park J, Choi H, Shin D, Kim J, Lee M, Kim S, et al. The effect of the dental root on single mandibular bone fractures. Arch Craniofac Surg 2018;19:190-3.

3. Choi KY, Yang JD, Chung HY, Cho BC. Current concepts in the mandibular condyle fracture management part I: overview of condylar fracture. Arch Plast Surg 2012;39:291-300.

4. Jung K, Lee JC, Kim J. Injury severity scoring system for trauma patients and trauma outcomes research in Korea. J Acute Care Surg 2016;6:11-7.

5. Casale GG, Fishero BA, Park SS, Sochor M, Heltzel SB, Christophel JJ. Classifying and standardizing panfacial trauma with a new bony facial trauma score. JAMA Facial Plast Surg 2017; 19:23-8.

6. Morrow BT, Samson TD, Schubert W, Mackay DR. Evidencebased medicine: mandible fractures. Plast Reconstr Surg 2014; 134:1381-90.
7. Park CH, Chung KJ, Kim TG, Lee JH, Kim IK, Kim YH. Big data statistical analysis of facial fractures in Korea. J Korean Med Sci 2020;35:e57.

8. Chung CM, Tak SW, Lim H, Cho SH, Lee JW. A retrospective computed tomography analysis of maxillary fractures and the clinical outcomes of their unreduced parts. Arch Craniofac Surg 2019;20:370-5.

9. Kim J, Choi JH, Chung YK, Kim SW. Panfacial bone fracture and medial to lateral approach. Arch Craniofac Surg 2016;17: 181-5.

10. Lee Y, Kim J, Lee M, Shin D, Choi H. Relationship between mandible fractures and third molars. Arch Craniofac Surg 2019;20:376-81.

11. Yu H, Jeon M, Kim Y, Choi Y. Epidemiology of violence in pediatric and adolescent nasal fracture compared with adult nasal fracture: an 8-year study. Arch Craniofac Surg 2019;20:228-32. 